\title{
Supply Chain Business System Reference Model: A Business Process Description Using IDEF0
}

\author{
Shigeki Umeda, Hu Bin \\ Musashi University, Tokyo Japan \\ shigeki@cc.musashiu.ac.jp
}

Key words Supply chain system, Enterprise model, Business Process Re-engineering

\begin{abstract}
This paper proposes a generic business process model for supply chain management. Effective operation of a supply-chain system requires frequent communication, information exchanges, among the member companies to achieve cooperative goals. Such business communication should include various kinds of data, such as ordering processes, manufacturing processes, transportation, product specification, quality, consumers' data, and so on. The objective of the model is to specify these process functions and their related information flows.
\end{abstract}

\section{INTRODUCTION}

Supply chain management is one of the keys to success in today's global manufacturing environment. Firms will need not only to cooperate with their vendors but with their vendor's vendors or supplier's suppliers, which are often firms in different countries. They must develop global strategies to coordinate operations at all phases of the value chain. Coordination of the supply chain will become strategically important as new forms of organizations - such as virtual enterprises, global manufacturing and logistic networks, and different company-to-company alliances - come into existence. Supply chain structures for these organizations will range from intra-firm stable networks to inter-firm dynamic networks.

Effective operation of a supply chain requires frequent information exchanges among the member companies in the chain to perform cooperative operations. Such business data communication should cover various kinds of operational data, such as product design, Bills Of Materials (BOM), operations directions, and process performance. Furthermore, the 
communication should include lots of planning data on operations. In some particular cases, these communications can be very complex because they contain confidential data from the chain members. Consequently, wellstructured communication protocols and security mechanisms are needed in ensure successful collaboration among the chain member companies.

A well-organized business process model is the basis for successful supply chain systems. Such a model must describe the planning and control of all major business operations in the view of entire chain. Coordination of these functions across the whole chain will be an important factor in the implementation of a well-structured supply chain.

This paper proposes a generic business-process model that describes the core business activities of a supply chain, information communications in the chain, and specifications of business data of the individual chain-member companies. This paper builds on some of the concepts described in [1]. One of its objectives is the description of business functions in the company organizations. The other is the identification of the communication interfaces among them for the definition of software application interfaces.

\section{MODELLING OF PLANNING AND CONTROL IN THE SUPPLY CHAIN}

Several models have been proposed to capture features and activities of manufacturing enterprises. CAM-I, ESPRIT/IMPACT, PERA, etc. are typical enterprise models that have been used to implement such computerintegrated environment [2]. ARIS is a framework that provides a methodology to model business processes and to configure enterprise information systems [3]. SEMATECH CIM-framework is an application framework based on object-oriented methods [4]. The scope of specifications in this model is restricted to shop floor operations within the semiconductor factories.

SCOR (Supply Chain Operations Reference model) is a framework for modelling the business and management processes in a supply chain [5]. SCOR defines the four core business processes, "PLAN", "SOURCE", "MAKE", and "DELIVER", and it defines twenty-four core process categories, which are used to assess the business process implementation. However, it does not provide descriptions of information exchange rules or information communication protocols.

Each of these models describes planning and control either within a single enterprise or across multiple enterprises. The coordination of these functions across member companies is critical to the construction of a powerful value chain. When a firm wants to exploit the potential of its 
manufacturing network to satisfy an order from a client, the firm has to configure that network and schedule the needed operations through that network to deliver the order at minimal cost and on time. The resulting network is a virtual supply chain composed of manufacturing plants, warehouses, and transportation firms.

Coordinated, optimal planning and control require efficient information exchanges among firms. These exchanges are critical to the development of plans and their subsequent implementation. Consequently, the new exchange protocols should be built to ensure the timely and accurate exchange of that information. Supply chains should be built on a strategic understanding of the topology of the network of member firms and on the capabilities of their business and manufacturing processes. Relations are established through formal and informal information exchanges between the different firms in the network.

The Japanese manufacturing companies are well known for the way they use information sharing to get their supply chains to be competitive. They have made information exchange a prime part of most of their manufacturing strategies, especially in the case of just-in-time implementation [6]. For example, Srinivason et al.[7] showed that in a justin-time environment, information exchange enhances shipment performance. Nishiguchi and Brookfiled [9] have described Japanese subcontracting practices. These are strongly based on collaborative, deep, true and real-time information exchange. Based on above discussions, this paper discusses a model for the planning and control operations for a supply chain. The model includes the information exchange protocols among the members of the chain.

\section{IMPLEMENTATION OF THE MODEL}

\subsection{IDEF0 modelling method}

The IDEF0 Function Modelling method is widely used to model the decisions, actions, and activities of an organization or system. It is also the most commonly used functional modelling method for analysing and communicating the functional perspective of a system. Effective IDEF0 models assist in organizing system analysis and promoting effective communication between the analyst and customer. Furthermore, the IDEF0 modelling method establishes the scope of analysis either for a current functional analysis or for future analyses from another system perspective. As a communication tool, IDEF0 enhances domain expert involvement and consensus decision-making through simplified graphical devices. As an 
analysis tool, IDEF0 assists the modeller in identifying the functions performed and the resources, in particular information, needed to perform them.

The basic activity element of an IDEF0 model diagram is represented by the simple syntax illustrated in Figure 1. A verb-based label placed in a box describes each activity. Inputs are shown as arrows entering the left side of the activity box while the outputs are shown as exiting arrows on the right side of the box. Controls are displayed as arrows entering the top of the box and mechanisms are displayed as arrows entering from the bottom of the box. Inputs, Controls, Outputs, and Mechanism are all referred to as concepts.

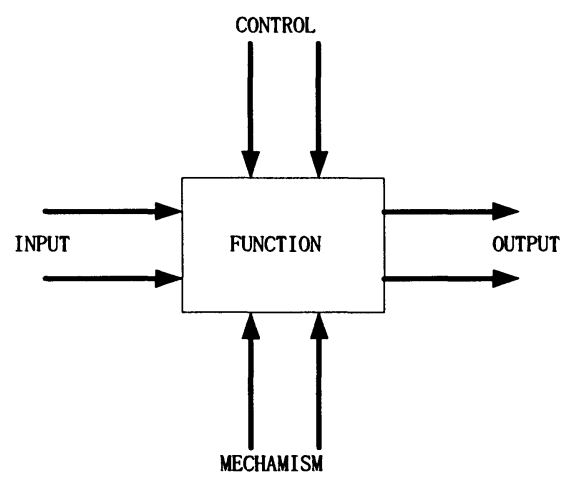

Figure.1 IDEF0 diagram

An IDEF0 model diagram is then composed of several activity boxes and related concepts to capture the overall function. IDEF0 not only captures the individual activities but also reveals the relationships between and among activities through the activities' related concepts. For example, the output of one activity may in turn become the input, control, or even a mechanism of another activity within the same model.

IDEF0 includes both a procedure and a language for constructing a layered model of the decisions, actions, and activities in an organization. Applying the IDEF0 method results in an organized representation of activities and important relations among them in a non-temporal, nondepartmentalised fashion. IDEF0 is designed to allow the user to "tell the story" of what an enterprise does.

\subsection{Supply chain business model}

The proposed model covers operations of discrete-typed supply chain firms, which pose the material inventory. The typical examples are automobile and electric companies. The core business processes of the 
whole of chain can be identified in the model. These are "Planning", "Execution", and "Monitoring". Each core process owns hierarchical structure, which is explored to the detail level. The "Planning" includes all of the activities, which make plans of operations in the chain. These include demands analysis, capacity assessment, purchasing planning, production planning, inventory planning, and transportation planning. The "Execution" includes all of the activities, which make products and deliver to customer. The "Monitoring" supervises the executed activities (Table.1 and Table.2)

Table.1 Definition of the functions in the model (1)

A0 Provides products to market in JIT

A1 Define the collaboration rules among the chain members

\begin{tabular}{|c|c|c|}
\hline & \multicolumn{2}{|r|}{ A11 Define business process rules among the chain members } \\
\hline & & A111 Define manufacturing rules \\
\hline & & A112 Define distribution rules \\
\hline & & A113 Define delivery rules \\
\hline & & A114 Define quality rules of deliverance \\
\hline & & A115 Define delivery stock rules \\
\hline & \multicolumn{2}{|r|}{ A12 Define information exchange rules among the chain members } \\
\hline & & A121 Define data formats \\
\hline & & A122 Define data interface formats \\
\hline & & A123 Define data exchange rules \\
\hline & & A124 Define data security rules \\
\hline \multicolumn{3}{|c|}{ A2 Plans production and distribution activities in the chain } \\
\hline \multicolumn{3}{|c|}{\begin{tabular}{l|l|} 
A21 Demand Planning \\
\cline { 2 - 2 }
\end{tabular}} \\
\hline & & A211 Make MTO Planning \\
\hline & & A212 Make MTS Planning \\
\hline & & A213 Make Demand Plans \\
\hline & \multicolumn{2}{|c|}{ A22 Supply Planning } \\
\hline & & A221 Supply capacity assessment \\
\hline & & A222 Material requirement planning \\
\hline & & A223 Supply capacity optimisation \\
\hline & & A224 Make supply plans \\
\hline & \multicolumn{2}{|r|}{ A23 Manufacturing Planning } \\
\hline & & A231 Make manufacturing plans of products \\
\hline & & A232 Make manufacturing plans of supplied parts \\
\hline & & A233 Make procurement plan \\
\hline & \multicolumn{2}{|r|}{ A24 Distribution Planning } \\
\hline & & A241 Make distribution plans of supplied parts \\
\hline & & A242 Make inventory plans of supplied parts \\
\hline & & A243 Make distribution plans of products \\
\hline
\end{tabular}

The model is composed of five sub-models. A1 is the function that defines rules of both business processes and information exchanges. This 
function provides collaboration rules of the chain member companies. Once this function would be executed, the defined rules will be used till the system configuration or environment is changed. A2 is the planning function of operational activities in the chain.

Table. 2 Definition of the functions in the model (2)

\begin{tabular}{|c|c|c|c|}
\hline & Provide & s produ & icts to market in JIT \\
\hline & $\mathrm{A} 3 \mathrm{~N}$ & Ianufac & tures products \\
\hline & & A31 & Procure materials \\
\hline & & & A311 Scheduling procurement \\
\hline & & & A312 Ordering purchase \\
\hline & & & A313 Receive materials and tests \\
\hline & & & A314 Records receipt of material \\
\hline & & & A315 Procurement accounting \\
\hline & & $\mathrm{A} 32$ & Manufacture products \\
\hline & & & A321 Scheduling manufacturing \\
\hline & & & A322 Manufacturing operations \\
\hline & & & A323 Maintenance manufacturing tools and equipment \\
\hline & & A33 & Transport products \\
\hline & & & A331 Scheduling transportation \\
\hline & & & A332 Withdraws products \\
\hline & & & A333 Transport operations \\
\hline & & & A334 Payment process \\
\hline & A4 D & stribute & es products \\
\hline & & A41 & Package products \\
\hline & & & A411 Scheduling packaging \\
\hline & & & \begin{tabular}{|l} 
A412 Packaging operations \\
\end{tabular} \\
\hline & & $\mathrm{A} 42$ & Deliver products \\
\hline & & & A421 Scheduling delivery \\
\hline & & & A422 Delivery operations \\
\hline & & & A423 Delivery/Inventory record processing \\
\hline & & $\mathrm{A} 43$ & Provide services \\
\hline & & & A431 Scheduling service activities \\
\hline & & & A432 Activate services \\
\hline & A5 $\mathrm{M}$ & onitor $\mathrm{c}$ & chain processes \\
\hline & & A51 & Monitor distribution of products \\
\hline & & A52 & Monitor manufacturing products \\
\hline & & A53 & Monitor service activities \\
\hline
\end{tabular}

The plans built in this function denote what procedures should be done in the chain. The demand planning (A21) is to make plans what items of products the members make, and how many volumes of products they make. The supply planning (A22) is to make plans how many volumes of parts they require, and when those parts should be supplied. The manufacturing planning (A23) is to make plans when the parts or products should be 
produced. Finally, the distribution planning (A24) is to make plans when the parts or products should be delivered, and how many volumes of parts or products should be stored. The "Manufactures products"(A3) defines manufacturing operations, which should be done in the suppliers, and the "Distribute products"(A4) defines distribution operations, respectively.

\subsection{Characteristics of the model}

This model is based on the decomposition of the "Chain" as a virtual enterprise, which is a group of companies. Individual business function is represented as the inputs, outputs, constraints (controls), and conditions (mechanism). The relations among the business functions are represented as a serious of block diagrams, which is straightforward to understand the process flow.

The model represents enterprise functions as a combination of core element models, which are planning, procurement, manufacture, and delivery. This model also represents the details of the business planning and control operations, which supervises all of processes in the whole of the chain. Individual communication protocol specifies the senders, the receivers, and the condition of them. The proposed model defined scheduledriven (push) system and buffer-driven (pull) system as the communication mechanism among the supply chain members. These specifications will support system integrators to define the communication interfaces among the business sections of the individual chain member company.

\section{Conclusion}

The proposed model is applicable as a reference model to represent company's organizations to perform BPR. The model can be used as a reference model to redesign business flows among the chain. The uniqueness is a definition of planning function whose scope the whole of the chain. Each process is breakdown of not the member firm but the chain. The model defines individual process of the business in the chain and information flows among them. These descriptions will especially help supply chain planners to understand chain-level planning functions.

The model will be also used as a reference model to build information system that support supply chain operation. Each element of the model (function) is hierarchical decomposition of activities. This hierarchical structure helps the practitioner keep the scope of the model within the boundaries represented by the decomposition of the activity. Therefore, the feature specified in individual model is applicable to specification of the module, when the practitioner designs software to support supply chain operation. This feature will be also applicable to define the communication 
protocols in the chain. The defined elements of the individual function such as input, output will be the definition of feature of interfaces among the modules.

This model will be also applicable as a framework to benchmarking of the individual process. Individual function specifies its inputs/outputs of materials and data. Accordingly, the indices can be defined to measure performance of the individual function. The practitioners can use the indices in order to review and improve their business processes continuously.

Supply chain system is an implementation of manufacturing enterprise integration. It needs generic frameworks to design and implement business processes and information systems. The main scope of current version is the representation of planning and controlling activities in the whole of the chain. We are currently expanding the models to describe the further detail levels. And we are also developing representation of the data structure definition by using IDEF1X modelling method. These will be also reference models to support supply chain implementation as well as the activities models.

\section{REFERENCES}

[1] Umeda, S. Jones, A. (1999) A Simulation-Based BPR Support Systems for Supply Chain Management, Reengineering in Action: The Quest for World-Class Excellence (Koong, C.M. eds.), 95-117

[2] Bernus, P., Nemes, L. eds. (1997) Modelling and Methodologies for Enterprise Integration, Chapman \& Hall

[3] Scheer, A.W. (1998) ARIS - Business process Frameworks, Springer

[4] SEMATECH, CIM Application Framework Specification 1.3, Tech. Transfer \#93061697F-ENG, 1996

[5] http://www.supply-chain.org/

[6] J.H. Dyer, W.G. Ouchi, Japanese-style partnerships: giving companies a competitive edge, Sloan Management Review, Fall 1993 (1993) 51-63.

[7] K. Srinivasan, K. Sunder, T. Mukhopadhyay, Impact of electronic data interchange technology on JIT shipments, Management Science 40 (10) (1994) 1291-1304.

[8] T. Nishiguchi, J. Brookfield, The evolution of Japanese subcontracting, Sloan Management Review Fall, 1998, pp. 89-101. 